SDNNi, LF và tỷ lệ LF/HF sau điêu trị tăng hơn so với trước điều trị ở bệnh nhân bệnh tim thiếu máu cục bộ mạn tính có suy tim.

\section{TÀI LIÊU THAM KHẢO}

1. Heikki V., Huikuri.,Timo H., et al. (2001). Heart rate variability in ischemic heart disease. autonomicneuroscience., 90 (1-2): 95-101.

2. Phạm Gia Khải và cộng sự. (2008). Khuyến cáo 2008 của Hô̂i Tim mach học Viêt Nam về bênh động mạch vành mạn tính. Khuyến cáo về các bệnh lý tim mạch và chuyển hóa. Nhà xuất bản $Y$ hoc:329-351.

3. Lề Thị Ngọc Hân và cộng sự. (2015). Nghiên cứu biến thiên nhip trên trên Holter điên tim 24 giờ ở bệnh nhân bệnh tim thiếu máu cục bộ mạn tính. J 108 Clin Med Pharm., 10 (6): 41-45.

4. Li H.R., Tse-Min Lu., Hao-Min Cheng., et al. (2016). Additive Value of Heart Rate Variability in Predicting Obstructive Coronary Artery Disease Beyond Framingham Risk. Circulation., 80: 494-501.

5. Akselrod S., Gordon D., Ubel F.A., et al.
(1981). Power spectrum analysis of heart rate fluctuation: a quantitative probe of beat-to-beat cardiovascular control. Science., 213 (4504): 220-222.

6. Björkander I.C., Forslund L.A., Kahan T.C., et al. (2008). Differential Index: A Simple Time Domain Heart Rate Variability Analysis with Prognostic Implications in Stable Angina. Cardiology., 111: 126-133.

7. Heikki R., Esa H., Niilo K., et al. (2009). Heart rate variability and stress hormones in novice and experienced parachutists anticipating a jump. Aviat Space Environ Med., 80 (11): 976-980.

8. Anand I., Ardell J. L., Gregory D., et al. (2020). Baseline NT-proBNP and responsiveness to autonomic regulation therapy in patients with heart failure and reduced ejection fraction. Int J Cardiol Heart Vasc., 29: 100520.

9. Stancheva N., Tisheva S., Jordanova V., et al. (2008). NT ProBNP and HRV and outcome in patients with heart failure with reduced vs. preserved systolic function. Journal of IMAB Annual Proceeding (Scientific Papers), 14: 89 - 94.

\title{
ĐÁNH GIÁ KẾT QUẢ XA TRI TOÀN NÃO ĐIỀU TRỊ CÁC TỔN THƯƠNG UNG THƯ PHỔI KHÔNG TẾ BÀO NHỎ DI CĂN NÃO
}

\section{TÓM TẮT}

Ung thư phổi (UTP) là một trong 3 ung thư thường gặp nhất và là nguyên nhân gây tử vong hàng đâu do ung thư trên phạm vi toàn cầu. UTP gồm 2 loại chính là UTP tế bào nhỏ (UTPTBN) và UTP không tế bào nhỏ (UTPKTBN). UTP giai đoạn tiến triển thường là di căn não. Đã có nhiêu thử nghiêm lâm sàng khác nhau đánh giá hiệu quả xạ trị toàn não đơn thuần trong điêu trị UTP di căn nã̃o và so sánh hiệu quả với các phương pháp điều trị khác. Kết quả đã chỉ ra rằng xạ trị toàn não đớn thuần giúp kiểm soát nhanh chóng và̀ giảm nhẹ các triệu chứng chèn ép thần kinh, nâng cao chất lượing sống cho bệnh nhân (BN). Đối tượng và phương pháp: 32 BN UTPKTBN di căn não 1-3 ổ, đường kính lớn nhất $\leq 30 \mathrm{~mm}$, được xạ trị toàn não 30 Gy với phân liều 3Gy/ngày, 5 ngày/tuần. Đánh giá kết quả sau xạ trị. Kết quả: Xạ trị toàn não đơn thuần làm biến mất tổn thương di cẳn não $6,2 \%$, giảm kích thước ổ di căn $(53,2 \%)$, kiểm soát ổ di căn ở $96,9 \%$ $\mathrm{BN}$. Xạ trị toàn não đơn thuần giúp cải thiện chỉ số PS ở 84,4\%; tỷ lệ BN có giảm các triệu chứng cơ năng chiếm $62,5 \%$, trong đó có $12,5 \%$ BN hết hoàn toàn triệu chứng. Kết luận: Xạ trị toàn não đơn thuần giúp

\section{${ }^{1}$ Bênh viên $K$}

Chịu trách nhiệm chính: Đồng Văn Hưởng

Email: dongnhangiabao@gmail.com

Ngày nhận bài: 3.8.2021

Ngày phản biên khoa học: 4.10 .2021

Ngày duyệt bài: 12.10.2021
Đồng Văn Hưởng ${ }^{1}$, Đinh Công Định' ${ }^{1}$, Nguyễn Văn Long1, Nguyễn Lan Phương1

kiểm soát nhanh chóng và giảm nhẹ triệu chứng chèn ép thần kinh nội sọ, giúp nâng cao chất lượng sống cho BN.

\section{SUMMARY \\ EVALUATING THE RESULTS OF WHOLE \\ BRAIN RADIOTHERAPY OF NSCLC'S BRAIN METASTATIC LESSIONS}

Lung cancer is one of three most common cancer disease and also is main cause of mortality worldwide. It includes two main types, one is small cell lung cancer (SCLC) and the other is non-small cell lung cancer (NSCLC). Advanced stage-lung cancer normally develops brain metastasis. There have been many different clinical trials to evaluate results of whole brain radiotherapy alone (WBRT Alone) in treatment of lung cancer's brain metastasis and compared with other therapies. It's shown that WBRT Alone can help to manage and to reduce the symptoms of intracranial pressure so that the patients' life-quality improved. Patients and methods: Including 32 patients NSCLC with brain metastasis. There are from one to three lesions with maximum diameter $\leq 30 \mathrm{~mm}$. WBRT Alone with 30Gy, the fraction is $3 G y /$ day and 5 days/week. The results were evaluated after radiotherapy. Results: $6,2 \%$ brain metastasis disappeared completely. The sizes of brain metastasis lesions reduces $53,2 \%$ and also $96,9 \%$ of those are controlled. After WBRT Alone was given, $84,4 \%$ of patients'PS are improved and also subjective symptoms of $62,5 \%$ of patients reduced and $12,5 \%$ of 
patients among them without any symptoms. Conclusion: WBRT could help to manage and to reduce the symptoms of intra-cranial pressure so that the patients' life-quality are improved.

\section{I. ĐẶT VẤN ĐỀ}

UTP là một trong 3 ung thư thường gặp nhất và là nguyên nhân gây tử vong hàng đầu do ung thư trên phạm vi toàn câu. Theo GLOBOCAN 2020 ở Việt Nam, số ca mắc mới ở cả 2 giới thuộc mọi lứa tuổi là 26.262 chiếm $14,4 \%$, số ca tử vong là 23.797 đứng thứ 2 sau ung thư gan. UTP gồm 2 loại chính là UTPTBN (10-15\%) và UTPKTBN (85-90\%).

Đặc điểm của UTP giai đoạn tiến triển thường là di căn não (30\%-50\% các trường hợp di căn não, có nguồn gốc từ phổi).

Đã có nhiêu thử nghiệm lâm sàng khác nhau đánh giá hiệu quả xạ trị toàn não đơn thuần trong điều trị UTP di căn não và so sánh hiệu quả với các phương pháp điều trị khác. Kết quả đã chỉ ra rằng xạ trị toàn não đơn thuần giúp kiểm soát nhanh chóng và giảm nhẹ các triệu chứng chèn ép thần kinh, nâng cao chất lượng sống cho bệnh nhân.

Vì vậy, chúng tôi tiến hành nghiên cứu đề tài: "Đánh giá kết quả xạ trị toàn não điều trị các tổn thương ung thư phổi không tế bào nhỏ di căn não tại Bệnh viện K" với 2 mục tiêu:

1. Mồ tả một số đặc điểm lâm sàng, cận lâm sàng ở bệnh nhân UTPKTBN di căn não tại bệnh viên $K$ từ 4/2021 đến 10/2021.

2. Đánh giá kết quả xạ trị toàn não tôn thương UTPKTBN di căn não.

\section{II. ĐỐI TƯƠNG VÀ PHƯƠNG PHÁP NGHIÊN CỨU}

Đối tượng nghiên cứu. BN được chẩn đoán UTPKTBN di căn não 1-3 ổ, được xạ trị toàn não tại Khoa xạ Quán Sứ-Bệnh viện K từ 4/2021 đến 10/2021.

Tiêu chuẩn lựa chọn: - Các BN được chẩn đoán xác định là UTP có kết quả mô bệnh học là ung thư biểu mô (UTBM) không tế bào nhỏ.

- BN đã hoặc đang điều trị u nguyên phát, hiện tại ổn định.

- Trên phim MRI não có di căn 1-3 ổ, đường kính lớn nhất mỗi ổ $\leq 30 \mathrm{~mm}$.

- Chỉ số toàn trạng PS=0;1;2;3 theo ECOG.

- Tự nguyện tham gia nghiên cứu.

- BN có hồ sơ lưu trữ đầy đủ.

Tiêu chuẩn loại trừ: - $\mathrm{BN}$ có kết quả mô bệnh học là UTBM tế bào nhỏ.

- BN có di căn thêm ở cơ quan khác ngoài não.

- BN không đồng ý hoăcc bỏ dở điều trị.

- BN có hồ sơ lưu trữ không đầy đủ.

Phương pháp nghiên cứu: mô tả cắt ngang, chọn mẫu thuận tiện.

Các bước tiến hành: khám lâm sàng, cận

lâm sàng trước điều trị

* Các dữ liệu về lâm sàng

Các BN tham gia nghiên cứu đều được khám lâm sàng tỉ mỉ, khai thác các triệu chứng tại chỗ, toàn thân và quản lý theo mẫu hồ sơ nghiên cứu.

- Đặc điểm chung: tuổi, giới, tiền sử hút thuốc, lý do vào viện, thời gian từ lúc có triệu chứng đâu tiên đến khi vào viện.

- Các triệu chứng cơ năng: đau đầu, nôn, buồn nôn, nhìn mờ, yếu chi, liệt, rối loạn trí nhớ, rối loạn vận đông ngôn ngữ.

- Các triệu chứng toàn thân: $\mathrm{PS}=0 ; 1 ; 2 ; 3$, sút cân

- Các triệu chứng thực thể: hội chứng tăng áp lực nội sọ, liệt nửa người, hội chứng tiểu não.

*Các dữ liệu cận lâm sàng:

- Tổn thướng di căn tại não: vị trí, số lượng, kích thước trên MRI sọ não.

- Các chất chỉ điểm khối u: CEA, Cyfra 21-1

- Kết quả mô bệnh học: UTBM vảy, UTBM tuyến, UTBM tế bào lớn.

Quá trình điều trị

- Tia xạ toàn não bằng kỹ thuật 3D-CRT

- Tổng liều 30Gy; phân liều 3Gy/ngày; 5 ngày/tuần

Đánh giá kết quả điêu trị với các yếu tố liên quan

- Thời điểm đánh giá: Sau xạ trị 30Gy

- Thông tin đánh giá: lâm sàng, cận lâm sàng, so sánh trước và sau xạ trị.

- Đánh giá đáp ứng với xạ trị: cơ năng, thực thể theo WHO và RECIST

- Phân tích một số yễu tố liên quan với đáp ứng điều trị: Đặc điểm chung của các $B N$, chỉ số toàn trạng, tình trạng bệnh, tính chất khối u, mô bệnh học...

Xử trí các tình huống trong và sau khi điều trị: phù não, co giật...

Phương pháp thu thập và xử lý số liệu

- Thu thập theo mẫu bệnh án nghiên cứu

- Phân tích và xử lý số liệu trên phần mềm SPSS 20.0.

\section{KẾT QUẢ NGHIÊN CỨU VÀ BÀN LUÂN}

Một số đặc điểm lâm sàng, cận lâm sang. Trong số $32 \mathrm{BN}$ nghiên cứu, phần lớn $\mathrm{BN}$ ở nhóm tuổi > 40 chiếm 90,7\%, lứa tuổi hay gặp

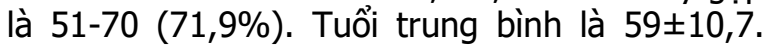
Kết quả này phù hợp với nhiều nghiên cứu trước đây về UTP. Tỷ lệ BN trên 40 tuổi trong nghiên cứu của Nguyển Hoài Nga, Bùi Diệu, Trân Văn Thuấn (2011, $\mathrm{n}=11.555)$ là $94,6 \%$; của Lê Duy Sơn $(2017, n=64)$ là 93,7\%. Như vậy, giống UTP 
nói chung, UTP di căn não cũng thường được phát hiện ở độ tuổi $>40$.

Nghiên cứu của chúng tôi thấy UTPKTBN di căn não gặp ở nam nhiêuu hơn nữ với tỷ lệ nam/nữ là 4,3/1. Nghiên cứu của Nguyễn Thanh Phương (2012) trên 30 UTP di căn não, tỷ lệ nam/nữ là 2,8/1; Nghiên cứu cứu của Lê Duy Sơn (2017) trên 64 BN tỷ lệ nam/nữ là 3,9/1.

Nghiên cứu về tình trạng hút thuốc lá ở Việt Nam của các tác giả Lê Tuấn Anh (2013) tỷ lệ sử dụng thuốc lá là $88 \%$; Lê Duy Sơn (2017) là $70,3 \%$. Nghiên cứu của chúng tôi thấy $71,9 \%$ BN có tiền sử hút thuốc lá, thuốc lào. Trong đó, tỷ lệ hút thuốc ở nam là $88,5 \%$, nữ $0 \%$, tương tự kết quả của Lê Duy Sơn là $88,2 \%$.

Phần lớn $\mathrm{BN}$ đến viện trong vòng $>4$ tuần kể từ khi có triệu chứng đầu tiên, chiếm 37,5\%. Điều này cho thấy, mặc dù $B N$ đến các cơ sở y tế sớm để được khám và chẩn đoán nhưng bệnh đã ở giai đoạn muộn.

Trong nghiền cứu của chúng tôi, $100 \%$ có triệu chứng đau đầu. Nôn, buồn nôn chiếm $93,8 \%$. Giảm thị lực $53,1 \%$, yếu chi $50 \%$, liệt $18,8 \%$, suy giảm trí nhớ $37,5 \%$, rối loạn vận động ngôn ngữ 34,4\%. Theo nghiên cứu của Lê Duy Sơn, đau đâu là $100 \%$; nôn, buồn nôn $92,2 \%$; yếu chi $50 \%$; liệt $17,2 \%$; suy giảm trí nhớ 39,1\%; rối loạn vận động ngôn ngữ 35,9\%.

Có $18,8 \%$ BN có triệu chứng liệt nửa người và cũng là lý do mà BN đến viện. Nghiên cứu của Nguyễn Thanh Phương (2013) tỷ lệ này là 20\%, tương tự như nghiên cứu của chúng tôi. Các BN này đều có di căn ở bán cầu đại não, kích thước ổ di căn $>20 \mathrm{~mm}$, xung quanh có phù não rộng.

Trong nghiên cứu này, đa số các $B N$ có chỉ số $\mathrm{PS}=2$ chiếm 43,7\%; $\mathrm{PS}=1$ chiếm 34,4\%; $\mathrm{PS}=3$ chiếm $21,9 \%$. Sau điều trị, BN có xu hướng giảm nhẹ triệu chứng, tuy nhiên có một số $\mathrm{BN}$ tiến triển nên xuất hiện $\mathrm{PS}=4$.

Trong số 32 BN nghiên cứu, di căn não 1 ổ chiếm $46,9 \%$, cao hơn so với loại 2 ổ $(25 \%)$ và 3 ổ $(28,1 \%)$. Theo Khosla, $50 \%$ các trường hợp di căn não là 1 ổ, $20 \%$ là 2 ố, $30 \%$ là từ 3 ổ trở lên. Nghiên cứu vị trí ổ di căn não trên MRI não cho thấy, trong $32 \mathrm{BN}$ có $71,9 \%$ BN di căn ở bán cầu đại não; $21,9 \%$ di căn tiểu não và $6,2 \%$ di căn ở cả 2 vị trí. Eichler, Loeffler (2007) phân tích trên tổng số 133 ổ di căn não ở 81 BN, vị trí di căn não hay gặp nhất là ở bán cầu đại não $(80 \%)$, kế đến là tiểu não $(15 \%)$, thân não (5\%). Nghiên cứu của chúng tôi có $62,5 \%$ BN có kích thước ổ di căn $<20 \mathrm{~mm}$, còn lại $37,5 \%$ là từ 20-30mm, 3 BN có kích thước ổ di căn não $<10 \mathrm{~mm}$.

Áp dụng phân loại mô bệnh học của WHO2015 cho UTP, trong nghiên cứu của chúng tôi thấy 21/32 BN UTBM tuyến $(65,6 \%) ; 34,4 \%$ UTBM vảy. Tỷ lệ UTBM tuyến trong UTP nói chung khác nhau tùy từng nghiên cứu nhưng đều có đặc điểm chung đây là loại mô bệnh học thường gặp nhất trong các báo cáo gần đây. UTBM tuyến thường hay di căn não nhiều hơn UTBM vảy.

Kết quả của chúng tôi cho thây nồng độ CEA trung vị trong huyết thanh là $8,7 \mathrm{ng} / \mathrm{ml}$. Tỷ lệ bệnh nhân có CEA >5ng/ml (độ nhạy) là $67,7 \%$, trong đó bệnh nhân có CEA $>20 \mathrm{ng} / \mathrm{ml}$, chiếm $25 \%$. Độ nhậy của CEA trong nghiên cứu của chúng tổi thẩp hơn kết quả của Lê Ngọc Hùng, Trần Minh Thông (2013) $(81,2 \%)$ do nghiên cứu này lấy ngưỡng là $3 \mathrm{ng} / \mathrm{ml}$.

Đánh giá kêt quả sau xạ trị toàn não 30Gy Bảng 1: Đáp ứng cơ nằng

\begin{tabular}{|c|c|c|}
\hline Đáp ứng cơ năng & $\mathbf{n}$ & Tỷ lệ \%o \\
\hline Hết hoàn toàn & 4 & 12,5 \\
\hline Thuyên giảm một phần & 16 & 50 \\
\hline Không thay đổi & 11 & 34,4 \\
\hline Tiến triê̂n & 1 & 3,1 \\
\hline Tống số & $\mathbf{3 2}$ & $\mathbf{1 0 0} \%$ \\
\hline
\end{tabular}

Bảng 1 cho thấy tất cả các $B N$ đều có biểu hiện triệu chứng khi vào viện. Đặc biệt là triệu chứng thần kinh làm cho BN lo lắng, khó chịu, ảnh hưởng nghiêm trọng đến chất lượng sống (rối loạn ý thức, suy giảm trí nhớ, hạn chế vận động...).

Theo dõi trong và sau khi kết thúc xạ trị $30 G y$, chúng tôi thây $20 / 32(62,5 \%)$ BN có đáp ứng với xạ trị, trong đó $4 \mathrm{BN}$ chiếm $12,5 \%$ hết hoàn toàn triệu chứng chủ quan. Điều này khẳng định tác dụng của xạ trị đã giúp cải thiện triệu chứng thần kinh và làm tăng tỳ lệ đáp ứng chủ quan ở BN UTPKTBN di căn não.

Bảng 2: Thay đổi triệu chứng cơ năng sau xạ trị

\begin{tabular}{|c|c|c|c|c|c|}
\hline \multirow{2}{*}{ Triệu chứng } & \multirow{2}{*}{$\begin{array}{c}\text { Số bệnh } \\
\text { nhân trước } \\
\text { điêu trị }\end{array}$} & $\begin{array}{c}\text { Giảm hoàn } \\
\text { toàn }\end{array}$ & $\begin{array}{c}\text { Giảm mốn } \\
\text { phần }\end{array}$ & $\begin{array}{c}\text { Không } \\
\text { thay đổi }\end{array}$ & $\begin{array}{c}\text { Tiến } \\
\text { triển }\end{array}$ \\
\hline Dau đầu & 32 & 11 & 20 & 1 & 0 \\
\hline Nôn, buồn nôn & 30 & 13 & 15 & 2 & 0 \\
\hline Phù̀ gai thị & 17 & 2 & 10 & 5 & 0 \\
\hline Yếu chi & 15 & 1 & 11 & 3 & 0 \\
\hline
\end{tabular}


VIETNAM MEDICAL JOURNAL N¹ - NOVEMBER - 2021

\begin{tabular}{|c|c|c|c|c|c|}
\hline Liệt & 5 & 1 & 1 & 3 & 0 \\
\hline Suy giảm trí nhớ & 13 & 4 & 3 & 5 & 1 \\
\hline Rối loạn vận động ngôn ngữ & 12 & 2 & 3 & 6 & 1 \\
\hline Tống số & $\mathbf{3 2}$ & \multicolumn{4}{|c|}{$\mathbf{1 0 0 \%}$} \\
\hline
\end{tabular}

Sau khi kết thúc xạ trị, tỷ lệ đau đâu giảm từ $100 \%$ xuống còn $65,6 \%$, trong đó đau đâu nhẹ là $62,5 \%$. Nôn, buồn nôn giảm từ $92,2 \%$ xuống còn $53,1 \%$. Nhìn mờ giảm từ $53,1 \%$ xuống còn $46,8 \%$. Yếu chi giảm từ $50 \%$ xuống còn $43,7 \%$ trong đó giảm một phân là 34,4\%, liệt giảm từ $18,8 \%$ xuống còn $12,5 \%$.Suy giảm trí nhớ giảm $37,5 \%$ xuống còn 28,1\%. Rối loạn vận động ngôn ngữ giảm từ 34,4\% xuống còn 31,2\%. Kết quả này cũng tương tự với nghiên cứu của Lê Duy Sơn, Nguyễn Ngọc Anh và Cs và một số nghiên cứu của các tác giả nước ngoài.

Bảng 3: Đáp ứng thực thể sau xạ trị trên MRI não

\begin{tabular}{|c|c|c|}
\hline Đáp ứng thực thề & $\mathbf{n}$ & Tỷ lệ \% \\
\hline Đáp ứng hoàn toàn & 2 & 6,2 \\
\hline Đáp ứng một phần & 17 & 53,2 \\
\hline Không thay đổi & 12 & 37,5 \\
\hline Tiến triển & 1 & 3,1 \\
\hline Tổng số & $\mathbf{3 2}$ & $\mathbf{1 0 0}$ \\
\hline
\end{tabular}

Đánh giá đáp ứng theo RECIST qua khám lâm sàng, cận lâm sàng (chụp MRI sọ não). Kết quả nghiên cứu của chúng tôi cho thây có 2/32 BN chiếm $6,2 \%$ các tổn thương não đáp ứng hoàn toàn sau khi chụp MRI sọ não. Đáp ứng một phần chiếm 53,2\%. Tuy nhiên, tỷ lệ không đáp ứng và bệnh tiến triển trong nghiên cứu của chúng tôi là $40,6 \%$. BN tiến triển là xuất hiện di căn mới.

\section{Bảng 4: Các hình ảnh cận lâm sàng sau xạ trị}

\begin{tabular}{|c|c|c|c|c|}
\hline \multirow[b]{2}{*}{ Hình ảnh cận lâm sàng } & \multicolumn{2}{|c|}{ Số bệ̀nh nhân } & \multicolumn{2}{|c|}{ Tỷ lệ \% } \\
\hline & $\begin{array}{l}\text { Trước } \\
\text { điều trị }\end{array}$ & $\begin{array}{c}\text { Sau } \\
\text { điêu trị }\end{array}$ & $\begin{array}{l}\text { Trước } \\
\text { điêu trị }\end{array}$ & $\begin{array}{l}\text { Sau } \\
\text { điều trị }\end{array}$ \\
\hline Tốn thương não một ố & 15 & 18 & 46,9 & 56,2 \\
\hline Tốn thương não đa ố & 17 & 12 & 53,1 & 37,6 \\
\hline Không còn tốn thương & & 2 & & 6,2 \\
\hline $\begin{aligned} \text { Phù não: } & + \text { Hết } \\
& + \text { Giảm }\end{aligned}$ & 32 & $\begin{array}{c}6 \\
26\end{array}$ & 100 & $\begin{array}{l}18,8 \\
81,2\end{array}$ \\
\hline Tống số & \multicolumn{2}{|c|}{32} & \multicolumn{2}{|c|}{100} \\
\hline
\end{tabular}

Bảng 4 cho thấy, sau xạ trị số BN hết tổn thương chiếm 6,2\%; tổn thương đa ổ giảm từ $53,1 \%$ xuống $37,6 \% ; 18,8 \%$ số BN hết phù não và $81,2 \%$ số BN giảm phù não.

Bảng 5: Thay đổi kích thước ổ tổn thương di căn não sau xạ trị

\begin{tabular}{|c|c|c|c|c|}
\hline \multirow{2}{*}{ Kích thước $(\mathrm{mm}) \quad$ Thời điểm } & \multicolumn{2}{|c|}{ Trước xạ trị } & \multicolumn{2}{|c|}{ Sau xạ trị } \\
\hline & $\mathbf{n}$ & Tỷ lê \% & $\mathbf{n}$ & Tỷ lê \% \\
\hline$<10 \mathrm{~mm}$ & 3 & 9,4 & 11 & 34,4 \\
\hline $10-19 \mathrm{~mm}$ & 17 & 53,1 & 12 & 37,5 \\
\hline $20-30 \mathrm{~mm}$ & 12 & 37,5 & 7 & 21,9 \\
\hline Hết tốn thương & & & 2 & 6,2 \\
\hline Tống số & 32 & 100 & 32 & 100 \\
\hline Kích thước trung bình & \multicolumn{2}{|c|}{$22,7 \pm 6,28$} & \multicolumn{2}{|c|}{$17,6 \pm 8,85$} \\
\hline
\end{tabular}

Bảng 5 cho thấy, kích thước trung bình của ố di căn não sau xạ trị nhỏ hơn có ý nghĩa so với trước điều trị $(17,6 \pm 8,85$ so với $22,7 \pm 6,28 ; p=0,001)$. Trong số $32 \mathrm{BN}$ trước điều trị, có $3 \mathrm{BN}$ đường kính ổ di căn não $<10 \mathrm{~mm}$, chiếm $9,4 \%$. Sau điều trị, các ổ di căn thu nhỏ kích thước nên tỷ lệ này là $34,4 \%$, và có $2 \mathrm{BN}$ hết hoàn toàn tổn thương, chiếm $6,2 \%$, cao hơn hẳn so với trước xạ trị. Sự khác biệt này có ý nghĩa thống kê $(p=0,001)$. Dưới tác động của bức xạ i-on hóa, các tế bào ung thư bị tiêu diệt, tổn thương di căn bị thoái hóa, hoại tử.

Bảng 6: Thay đổi về triệu chứng toàn thân

\begin{tabular}{|c|c|c|c|c|c|}
\hline \multirow{2}{*}{ Các yếu tố } & Đáp ứng & \multicolumn{2}{c|}{ Trước xạ trị } & \multicolumn{2}{c|}{ Sau xạ trị 30Gy } \\
\cline { 3 - 6 } & & $\mathbf{n}$ & $\mathbf{T}$ lệ \% & $\mathbf{n}$ & Tỹ lệ \% \\
\hline \multirow{3}{*}{$\begin{array}{c}\text { Chỉ số } \\
\text { toàn trạng }\end{array}$} & $\mathrm{PS}=1$ & 11 & 34,4 & 16 & 50 \\
\cline { 2 - 6 } & $\mathrm{PS}=2$ & 14 & 43,8 & 11 & 34,4 \\
\cline { 2 - 6 } & $\mathrm{PS}=3$ & 7 & 21,9 & 1 & 3,1 \\
\cline { 2 - 6 } & $\mathrm{PS}=4$ & 0 & 0 & 4 & 12,5 \\
\hline
\end{tabular}




\begin{tabular}{|c|c|c|c|c|}
\hline Sốt & 13 & 40,6 & 1 & 3,1 \\
\hline Sút cân & 13 & 40,6 & 0 & 100 \\
\hline
\end{tabular}

Bảng 6 cho thấy trước khi điều trị toàn trạng của $B N$ có $P S=1 ; 2 ; 3$ có tỷ lệ lân lượt là 32,8\%; $43,8 \% ; 23,4 \%$. Sau xạ trị, toàn trạng của BN đã thay đổi như sau: $P S=1 ; 2 ; 3$ có tỷ lệ lần lượt là $48,2 \% ; 34,4 \%$ và $4,8 \%$. Như vậy, tỷ lệ BN có $\mathrm{PS}=1$ tăng từ $32,8 \%$ lên $48,2 \%$ và $\mathrm{PS}=3$ giảm từ $23,4 \%$ xuống 4,8\%. Chứng tỏ chỉ số này của $B N$ được cải thiện sau xạ trị, khi xét mối liên quan giữa PS trước và sau xạ trị thì sự khác biệt này là có ý nghĩa thống kê với $p<0,05$.

\section{KẾT LUÂN}

Bệnh thường gặp ở nam giới (81,3\%), khoảng tuổi 51-70 chiếm 61,9\%, đến viện trong vòng hơn 1 tháng tính từ khi có triệu chứng (37,5\%). Triệu chứng phổ biến nhất là đau đâu $(100 \%)$; nôn và buôn nôn $(93,8 \%)$; yếu chi, liệt $(68,8 \%)$; tiên sử hút thuốc là $71,9 \%$ (ở nam là $88,5 \%)$.

Trên hình ảnh MRI so não, phân lớn tổn thương di căn ở bán câu đại não $(71,9 \%), 1$ ổ (46,9\%), kích thước 20-30mm (37,5\%).

Đa số BN là ung UTBM tuyến (65,6\%). Trong nhóm BN này $67,7 \%$ BN có CEA và $68,8 \%$ có Cyfra 21-1 huyết thanh cao hơn giới hạn bình thường.

WBRT làm biến mất tổn thương di căn não 6,2\%, thu nhỏ kích thước ổ di căn (53,2\%), kiểm soát tổn thương di căn ở 96,9\% BN.

WBRT giúp cải thiện chỉ số PS ở 84,4\%; tỷ lệ BN có thuyên giảm các triệu chứng cơ năng chiếm $62,5 \%$, trong đó có $12,5 \%$ BN hết hoàn toàn triệu chứng.

Tóm lại, WBRT giúp kiểm soát nhanh chóng và giảm nhẹ triệu chứng chèn ép thần kinh và nâng cao chất lượng sống cho BN.

\section{TÀI LIÊU THAM KHẢO}

1. Globocan 2020 Vietnam [Online] Gco.iarc.fr/ today/data/factsheets/populations/704-viet-namfact-sheets.pdf

2. Ngô Quý Châu (2008). Ung thư phổi. Nhà xuất bản Y học, Hà Nội, 28-288.

3. Nguyển Bá Đứ̛́c, Bùi Công Toàn, Trân Văn Thuấn (2007). Ung thư phổi. Chẩn đoán và điều trị bênh ung thư, Nhà xuất bản Y họ, Hà Nội, 176-187.

4. National Comprehensive Cancer Network (2021). Central Nervous System Cancers. Clinical practice guidelines in oncology, V.6.2021.

5. Nguyến Hoài Nga, Bùi Diệu, Trân Văn Thuấn, Bùi Công Toàn (2011). N̦hân xét một số đăc điểm dịch tễ, lâm sang, cận lâm sàng ung thư phổi nguyên phát. Tạp chí Ung thư học Việt Nam, số 3, 2011, 210-215.

6. Lê Duy Sơn (2017). Đánh giá kết quả xa trị gia tốc di căn não trong ung thư phế quản phổi. Luận văn thac sỹ Y họ, 59-68.

7. Edward S, Charles S, Luis S, et al (2000). Single dose radiosurgical treatment of recurrent previously irradiated primary brain tumors and brain metastases: final report of RTOG protocol 90-05. International Journal of Radiation Oncology. Biology. Physics, 47(2), 291-298.

8. Khosla A (2013). Brain metastases Imaging: Imaging. http://medicine.medscape.com

9. Eichler A.F, Loeffler J.S (2007). Multidisciplinary Management of Brain Metastases. The Oncologist, 12(7), 884-898.

\section{MộT SỐ CHİ Số TRÊN PHIM ĐO SỌ MĂT NGHIÊNG CỦA BÊ̂NH NHÂN SAI KHỚP CẮN LOẠI II}

\section{TÓM TẮT}

Mục tiêu: Đánh giá một số chỉ số trên phim đo so mặt của bệnh nhân có sai khớp cắn loại II do lùi xương hàm dưới. Đối tượng và phương pháp nghiên cứu: Nghiên cứu được thực hiện trên 46 phim đo sọ mặt của bệnh nhân có sai khớp cắn loại II do lùi hàm dưới, độ tuổi trung bình là 10-14 tuổi. Kết

\section{*Trướng Đại học Y Hà Nội}

Chịu trách nhiệm chính: Hoàng Việt Hải

Email: hoangviethai@hmu.edu.vn

Ngày nhận bài: 4.8.2021

Ngày phản biên khoa họ: 4.10 .2021

Ngày duyệt bài: 13.10.2021
Hoàng Việt Hải*

quả: Góc SNA tăng nhẹ $\left(83,6^{\circ}\right)$, góc SNB giảm $\left(75,9^{\circ}\right)$ cho thấy có sự lùi hàm dưới, góc ANB cao hơn bình thường $\left(6,5^{\circ}\right)$ cho thấy tương quan xương hai hàm loại II, góc liên răng cửa giảm, góc răng cửa trên và góc răng cửa dưới tăng $\left(114,4^{\circ}\right)$. Không có sự khác biệt có ý nghĩa thống kê về giới trong nhóm đối tượng nghiên cứu. Kết luâan: Hàm dưới lùi so với nền sọ trước, tương quan xương hai hàm loại II và trục răng cửa trên và dưới ngả trước.

Tư khoá: Phim đo sọ mặt, Sai khớp cắn loại II Lùi hàm dưới

\section{SUMMARY}

CEPHALOMETRIC CHARACTERISTICS OF PATIENTS WITH CLASS II MALOCCLUSION 